\title{
Governing risk elements through open pit slope optimization
}

\author{
by M. Golestanifar*, K. Ahangari*, K. Goshtasbi ${ }^{\dagger}$, \\ A. Akbari Dehkharghani ${ }^{\ddagger}$, and P. Terbrugge ${ }^{\S}$
}

\section{Synopsis}

With the increasing competition in global mineral markets, designers are attempting to drive down overall mining costs. The demands for steeper pit slopes have triggered developments in the field of modern and comprehensive slope design. Risk-based optimization techniques are one of the most challenging state-of-the-art solutions for enhancing conventional procedures. Recognizing risk aspects has a fundamental role in updating the methods. Considering geotechnical and mine planning issues, this study describes the consequences of varying slope angles on final pit walls. Twenty-three risk elements are introduced and discussed in four groups: economic, technical, strategic, and regulatory compliance. Related examples are given on the state of the elements, and possible ways to achieve them from overall slope optimization studies of the Sungun copper mine in Iran. The circumstances indicate that decisions on optimized slopes do not relate only to geotechnical studies, but that relevant consequences depend on the four groups. Evaluation of the elements can promote slope optimization based on the concepts of risk. Keywords

pit slope design, risk evaluation, slope stability, mine planning, Sungun copper mine.
Similarly, there are complicating criteria for probability of failure (PoF) in probabilistic design methods, which vary in the range from 0.003 to 0.3 (Wesseloo and Read, 2009). In addition to the uncertain nature of materials in slopes, different governing conditions around mining slopes are the main causes of variability.

In general, consequences of failure drive the evaluation of overall slope design, with the importance of equipment, personnel in the high-risk areas, related structures, loss of ore and production having a direct effect on the risk evaluation. Therefore, in order to achieve optimum slope angles, a robust system using multidimensional risk concepts is required. By considering the governing factors, trade-off models such as cost-benefit analyses are developed to assess the shortcomings of FoS and PoF analyses (SRK Consulting, 2006; Tapia et al., 2007). Furthermore, risk models can assist stakeholders in making the important decisions required for optimum slope design.

The probability of slope failure, $P$, and its consequences, $C$, are defined using risk assessment methods. Then, by comparing the calculated risk for various consequences with threshold limits, decisions are made on the desirability of design slope angles (Contreras, Le Sueur, and Maran, 2006). Since the steepest possible slopes are required, decisions are taken in the ALARP (as low as reasonably practical) zone. If the values of calculated risk fall above the threshold limit, various risk management decisions are required prior to

* Department of Mining Engineering, Science and Research Branch, Islamic Azad University, Tehran, Iran.

+ Faculty of Mining Engineering, Tarbiat Modares University, Tehran, Iran.

₹ Department of Mining Engineering, Islamic Azad University, Central Tehran Branch, Tehran, Iran.

§ SRK Consulting, South Africa.

(C) The Southern African Institute of Mining and Metallurgy, 2018. ISSN 2225-6253. Paper received Oct. 2012; revised paper received Jun. 2017. 


\section{Governing risk elements through open pit slope optimization}

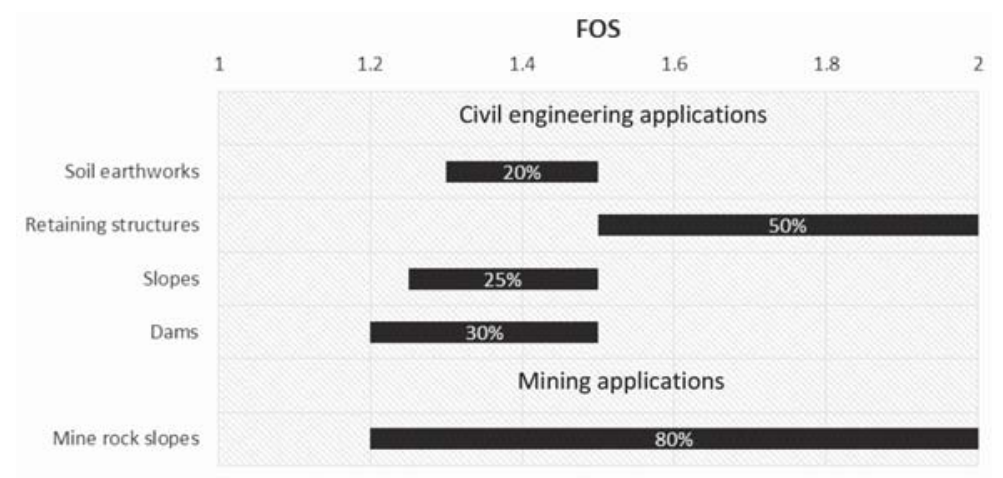

Figure 1-Range of the FoS for various applications of slope (Priest and Brown, 1983)

the slope designs being implemented. A flow chart of the risk evaluation method for slope design of open pits is included as Figure 2.

The objectivity of a risk assessment method is based on its recognized risk aspects, and in practice, risk elements are derived from reviewing events in a similar system and/or failure analysis, using fault trees or influence diagrams, in conceptual models. Since failure analyses require knowledge of real-world system responses, gathering data on global events in pit slope instability is a vital step for anticipating various elements in the multi-factor risk model. Unfortunately, comprehensive published reporting of the consequences of pit slope failures is limited. Current reports do include specific concerns on elements such as fatalities and injuries to personnel, but seldom divulge appropriate information on other consequences of failure, including the economic consequences. The current research is dedicated to defining the categorized effective risk elements in optimization of pit slope through several practical cases from the Sungun copper mine, Iran.

A literature review on risk analysis procedures and embedded risk elements is included in the next section, followed by an overview of the Sungun mine as a case study. New risk elements are classified into economic, technical, strategic, and regulatory categories and discussed in conjunction with related examples for the Sungun mine.

\section{Literature review}

Contreras, Le Sueur, and Maran (2006) used a bow-tie diagram for evaluating the variability in slope design parameters at the Cerrejon coal mine, Columbia, with the probability of slope failure under normal conditions being assessed. By considering specific slope configurations, variability in parameters introduced and the PoF of the slopes calculated. The risk was calculated for each slope scenario by determining the various consequences of failure. Finally, a decision on appropriate slope angles was made by comparing the risk values with the defined thresholds.

Ideally, the optimum overall angle, followed by the interramp angle, should be selected by comparing the benefits gained (less stripping, more ore) with the potential costs (failure cleanup, downtime, ore losses, equipment damage, etc.) by steepening the slope, and followed by determining the angle providing the optimum economic slope (Ryan and Pryor, 2000). This approach is generally referred to as a cost-

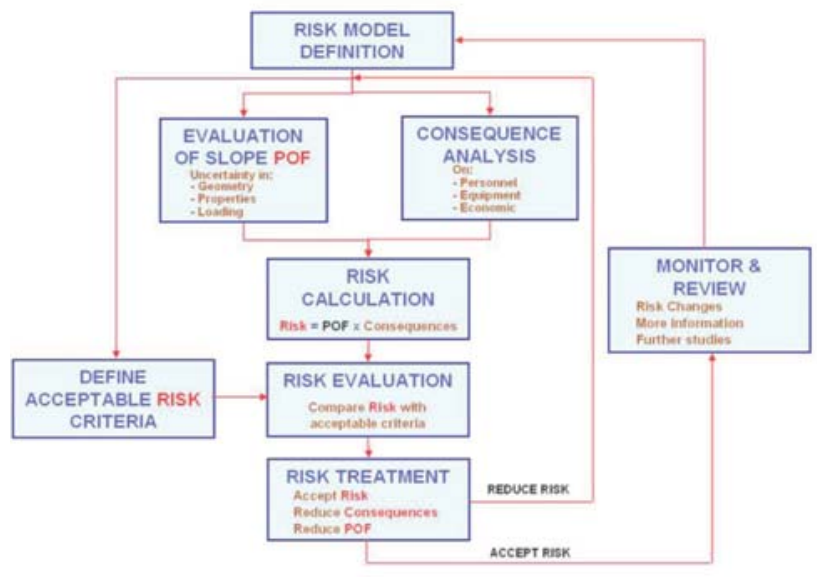

Figure 2-Slope design flow chart based on failure risk (Contreras, Le Sueur, and Maran. 2006)

benefit analysis (Call and Kim, 1978), and has been used successfully at several large porphyry copper mines to assist the mine planners in maximizing economic recoveries (Ryan and Pryor, 2000). Two general cost-benefit analyses have been used over the years: a long form and a short form, with the short form being used more frequently. The long form is a detailed process requiring significant work by the mine planners prior to the stability modelling process. The short form analysis addresses only the final wall and therefore requires much less work (Ryan and Pryor, 2000).

Generally, using cost-benefit methods in open pit mine design requires a large amount of data and calculations with accurate economic information, defined ramp locations, open pit NPVs, economic value of the last blocks on each mining level, unit cost of cleanup, cost of lost production, and cost of backfilling for ramp re-establishment. Moreover, there are a number of possible costs for specific cases such as the requirements for slope drainage, repair cost of installations, cost of railroad track recovery, repair cost of in-pit crushers and conveyor belts, and the requirements for access roads for underground structures (Dinis da Gama, 1994).

Appropriate numerical forecasting of the consequences of failure will be more complicated when various alternatives are available for the remediation of failures.

Contreras, Le Sueur, and Maran (2006) and Terbrugge et al. (2006) cover the major consequences of slope failure in a bow-tie diagram, including injury to personnel, damage to 


\section{Governing risk elements through open pit slope optimization}

equipment, economic impact on production, force majeure (a major economic impact), industrial action, and public relations, such as stakeholder resistance and environmental impact. They also consider that three of the six consequences are economic-related, although on different scales regarding the acceptable risk that would apply to each case.

In addition, Terbrugge et al. (2006) suggested more items to define economic consequence, being cleanup cost, slope remediation, haul road repair, equipment re-deployment, loss of ore, damage to equipment and infrastructure, cost associated with fatalities and injuries, and disruption of production.

Stacey (2009) categorized the main considerations in slope design of open pit mines into three groups:

> Safety/social factors, including loss of lives or injury, loss of worker's income, loss of workers' confidence, and loss of corporate credibility, both externally and among shareholders

$>$ Economic factors, including disruption of the operations, loss of ore, loss of equipment, increased stripping, cost of cleanup, and loss of market share

> Environmental/regulatory factors, including environmental impacts, increased regulation, and closure considerations.

\section{Sungun mine case study}

A case study of the Sungun mine in the northwest of Iran is used in order to illustrate the various risk elements that exist. The Sungun copper mine, containing more than $388 \mathrm{Mt}$ of copper ore with the average grade of $0.63 \%$, is one of the deepest open pit mines in Iran, with the final pit planned to a depth of approximately $700 \mathrm{~m}$ (Abbaszadeh et al., 2011). The location of the mine is shown in Figure 3.

As details on the risk assessment study for the mine comprise a large database, this paper considers only the RSO2 section of the southwestern wall. In this section the maximum height of the planned wall is $615 \mathrm{~m}$ with an overall slope angle of $29^{\circ}$ ( $32^{\circ}$ for a drained condition), an interramp slope angle of $37^{\circ}$ ( $42^{\circ}$ for a drained condition), and bench slope angles (BSAs) of $65^{\circ}$. The width of the catch berms is $38 \mathrm{~m}$ (30 m for drained condition), and the width of the geotechnical berm is $50 \mathrm{~m}$ (SRK Consulting, 2008). The geotechnical section of the RSO2 section is presented in Figure 3.

\section{Risk inventory}

In order to assess the overall risk, 23 risk elements for the Sungun case study have been recognized. The elements are classified into four groups: economic $(E)$, technical $(T)$, strategic $(S)$, and regulatory $(R)$. Table I summarizes the risk elements in these groups and the source of each element. Despite the previous studies considering only failure consequences, overall slope variations have been investigated from a design and mine planning viewpoint.
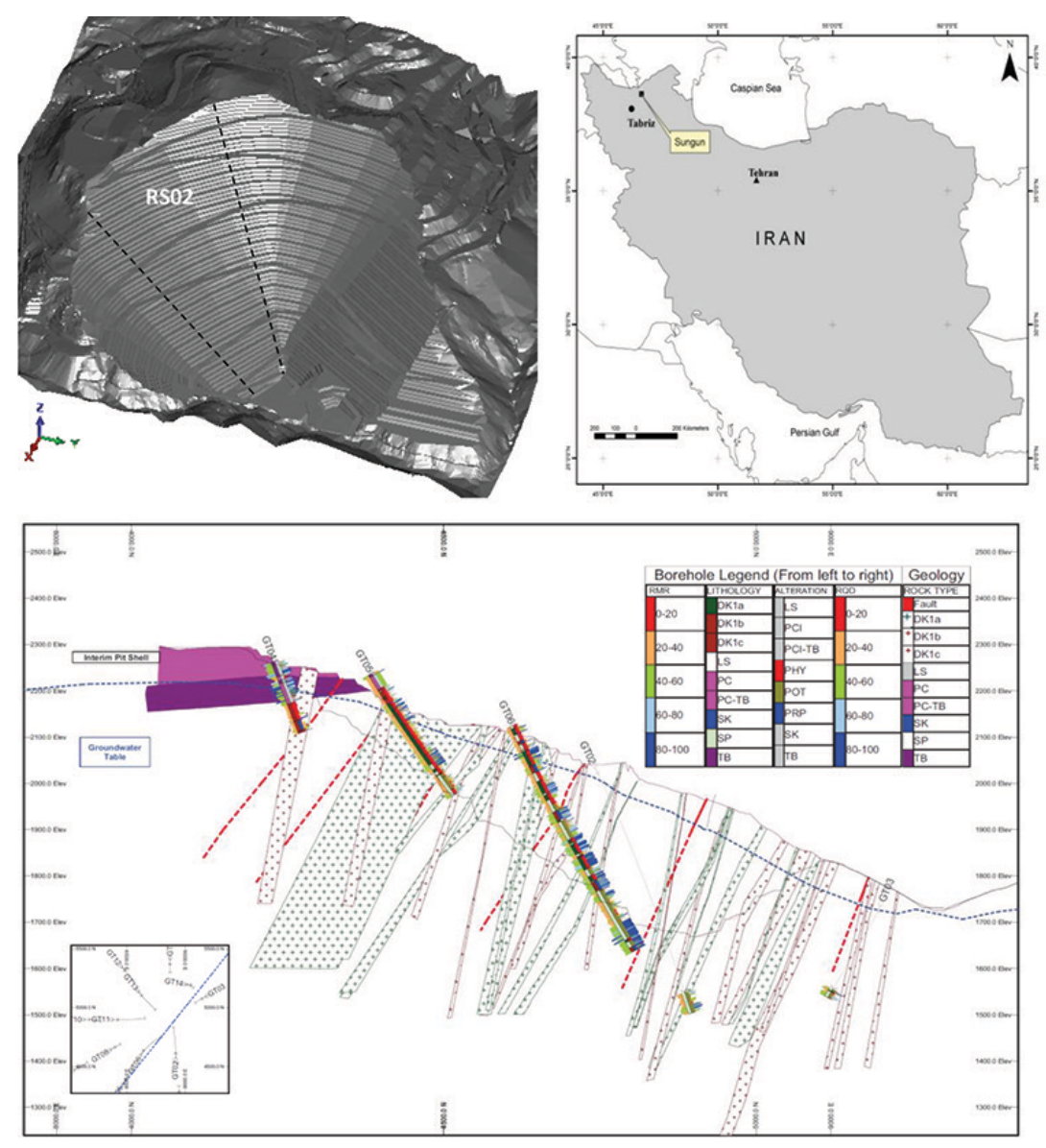

Figure 3-Location of the Sungun mine and details of the RS02 wall 


\section{Governing risk elements through open pit slope optimization}

\begin{tabular}{|c|c|c|c|}
\hline Category & Element & Source & Definition \\
\hline \multirow[t]{9}{*}{ Economic $(E)$} & $E_{1}$ & Design & Variation in pre-stripping tonnage \\
\hline & $E_{2}$ & Failure & Loss of or damage to equipment \\
\hline & $E_{3}$ & Failure & Ore loss due to dilution \\
\hline & $E_{4}$ & Failure & Requirement to re-establish drainage systems \\
\hline & $E_{5}$ & Failure & Backfill and ramp re-construction \\
\hline & $E_{6}$ & Failure & Clean-up volume or preparation for mine closure \\
\hline & $E_{7}$ & Design & Variations in stripping ratio \\
\hline & $E_{8}$ & Failure & Loss of profit due to production delays \\
\hline & $\mathrm{E}_{9}$ & Failure & The cost of cutback and/or support of the failed slope \\
\hline \multirow[t]{4}{*}{ Technical $(T)$} & $T_{1}$ & Design & Narrow ramps \\
\hline & $T_{2}$ & Failure & Incompatibility of mine fleet for clean-up \\
\hline & $T_{3}$ & Design & Increase in problems due to mining below the water table \\
\hline & $T_{4}$ & Failure & Effect of ramp loss \\
\hline \multirow[t]{4}{*}{ Strategic $(S)$} & $S_{1}$ & Failure & Loss of market share \\
\hline & $S_{2}$ & Failure & Contractual penalties \\
\hline & $S_{3}$ & Failure & Stakeholder confidence \\
\hline & $S_{4}$ & Failure & Political response \\
\hline \multirow[t]{6}{*}{ Regulatory (security - social - environmental) $(R)$} & $R_{1}$ & Failure & Fatalities within the workforce \\
\hline & $R_{2}$ & Failure & Injuries within the workforce \\
\hline & $R_{3}$ & Failure & Workforce confidence \\
\hline & $R_{4}$ & Failure & Increase of legislation \\
\hline & $R_{5}$ & Failure & Employment opportunity \\
\hline & $R_{6}$ & Design and Failure & Environmental impact (mine waste and failed material) \\
\hline
\end{tabular}

\section{Economic risks (E)}

Economic consequences could be generally defined as those that have a direct effect on the economics of the mine. These are categorized as follows.

\section{Variation in pre-stripping tonnage $\left(E_{1}\right)$}

The overall slope angle of a pit has an inverse relationship with the stripping ratio (W/O), with the amount of stripping divided into overburden (pre-stripping) and mining waste. Pre-stripping has a direct relationship with capital costs, and is investigated in the study as a separate element.

Based on the Sungun block model, with overburden of $150 \mathrm{~m}$ from the $2375 \mathrm{~m}$ level to the $2225 \mathrm{~m}$ level, by increasing the overall slope angle of the RS02 section from $29^{\circ}$, the design case, to $37^{\circ}$, pre-strip tonnage decreases, while the total waste and ore tonnages increase. However, the stripping ratio decreases from 1.86 to 1.75 , as shown in Figure 4.

As a general rule, an increase in overall slope angle (OSA) leads to lower stripping ratios. However, this does not always result in a reduction in the waste tonnage. Indeed, it permits the mine planner in certain cases to expand the pit limits or the total pit size with similar waste to ore ratios. In such a situation the total mineable volume increases, which leads to more ore and more waste tonnage, while the stripping ratio decreases or at least remains the same. A valid case is the porphyry deposit at Sungun, where the orebody extends to depth. The phenomenon is based on an improvement in the financials of the pit by steepening the OSA, where possible, which leads to the extraction of 'sterilized ore' not included in the original life of mine plans.

\section{Loss of, or damage to, equipment $\left(E_{2}\right)$}

The consequence of a failure for the mine fleet can be related to the magnitude of the failure, reliability of the monitoring system, and the pit evacuation procedures. An assessment of the proportion of the total investment in fleet which is divided between each section of the mine is required to evaluate this consequence. Techniques such as O'Hara's cost estimating model (O'Hara, 2008), and detailed cost calculations (Hustrulid and Kuchta, 1995) have been developed to evaluate the fleet capital investment. Since a complete and constant inventory of the mine fleet is not found in the case study, O'Hara's model is implemented to forecast approximate capital costs, first for the entire mine, and then specifically for the RSO2 section. Since a fifth of the

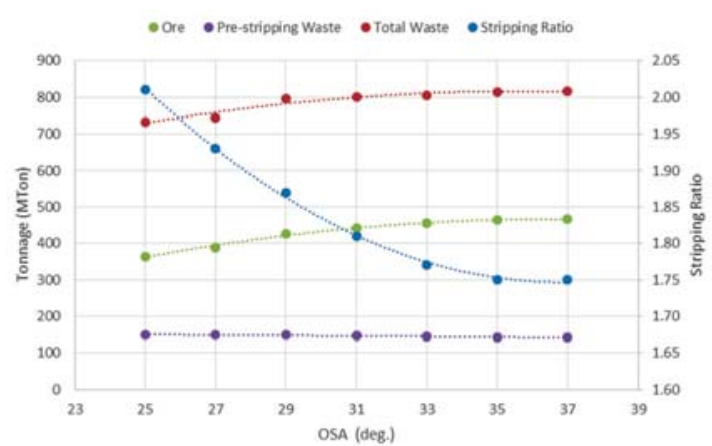

Figure 4-Variations of pre-stripping, strip ratio, and overall slope angle in the RS02 sector 


\section{Governing risk elements through open pit slope optimization}

rock tonnage is located in $\mathrm{RSO} 2$ section, it is expected that the same proportion of personnel and equipment will be concentrated in RSO2. Using an updated O'Hara model (Akbari and Osanloo, 2005), the capital cost for the RSO2 section is estimated at US\$44 million, and the workforce is estimated at 42 persons.

The likelihood of losing equipment is dependent on the effectiveness of the monitoring system and the evacuation procedures, which are obtained from an event tree as shown in Figure 5.

\section{Ore loss due to dilution $\left(E_{3}\right)$}

The dilution could be more than the permitted limit, depending on the failure mechanism, and generally, because of the conditions of the failed mass, it is not possible to separate ore from waste.

\section{Requirement to re-establish drainage systems $\left(E_{4}\right)$}

If a drainage system installed in the pit is at risk of being lost or damaged, this should be considered in the risk model. The damage to the drainage system is dependent on the volume and shape of the failure. If deep drainage systems such as long horizontal drains are used, the shape, and especially the depth, of failure are important. Damage resulting from movement of the failed zone is low when considering an expit dewatering system. Since the water table at Sungun mine is in the upper levels of the pit (1850 m level), the ex-pit dewatering system should be more robust. Therefore loss of the dewatering system is excluded from the analysis.

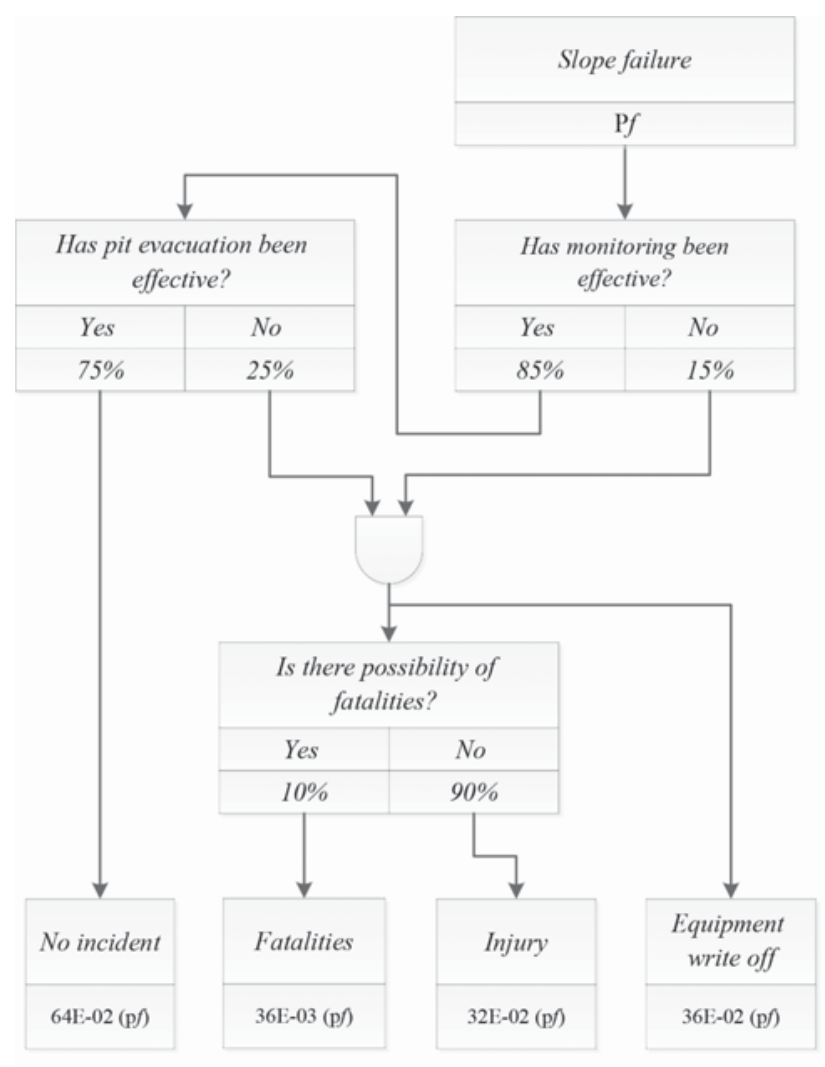

Figure 5-Consequences of failure for personnel and equipment (event tree method)

\section{Backfill and ramp reconstruction ( $\left.E_{5}\right)$}

If the slope failure includes main ramps, generally there are two solutions for restoring them, which may be applied individually or in combination. The first solution would be flattening the upper parts of the pit if possible and reconstructing the ramps. However, cutting back could exceed the optimum pit limit, although the stability of new ramps constructed in an undisturbed rock mass constitutes a major advantage. The second method includes backfilling and creating new ramps. This is mostly used when the volume of the required materials is low and requirements for stabilization are economically available. The economic risk of reconstructing ramps can be forecast by assessing the costs of the remedial measures.

\section{Cleanup volume or preparation for mine closure $\left(E_{6}\right)$}

Depending on the age of the mine, the severity of the failure, and other conditions, when a failure occurs the mine is faced with two alternatives. Firstly, cleanup in order to continue the mining operations, and secondly, leaving the remaining ore in situ and moving to the closure plan. Golestanifar (2011) developed a new concept of slope transmission level to solve this problem: for a given overall slope, when the mine reaches a specified level, failure could lead to mine closure. Based on decisions made after failure, item $E_{6}$ could be estimated according to cleanup costs and compared to mine closure costs.

\section{Variations in stripping ratio $\left(E_{7}\right)$}

Assuming that the failure can be mined at a lower level in the pit, a cutback may be required to stabilize the slope, which will have an impact on the stripping ratio. By steepening the overall slope, the total mineable tonnage, both ore and waste, will be increased. However, at first glance, the increase in waste could signify reduced profits, due to the increased rate of exploitation of mineable ore and decreased stripping ratio (Figure 4). Thus for a unit of ore, a lower waste tonnage needs to be mined. It should be noted that this relationship is true when the ore deposit extends deeper than the pit.

\section{Loss of profit due to production delays $\left(E_{8}\right)$}

If a failure occurs in a critical area, production will probably be delayed due to the time required for cleanup, with the mine life being prolonged artificially. The duration of cleanup tasks depends on volumes and available equipment, and therefore, the current present value of profit, $P_{p}$, could be reduced by using a lump sum value, as in Equation [1] (Hustrulid and Kuchta, 1995).

$$
P_{p}=P_{F}\left[\frac{1}{(1+i)^{n}}\right]
$$

where $P_{F}$ is the future profit of postponed production, $i$ is the annual discount rate, and $n$ is the delay in years. Therefore, a decrease in profit value, Loss, could be estimated by multiplying the loss factor, $L$ (Equation [2]) by $P_{F}$ as in Equation [3].

$$
\begin{aligned}
& L=1-\left(\frac{1}{(1+i)^{n}}\right) \\
& \text { Loss }=L \times P_{F}
\end{aligned}
$$




\section{Governing risk elements through open pit slope optimization}

This forecasting is valid when no stockpile exists in the mine, although issues such as blending might be raised.

\section{Cost of cutback and/or support of the failed slope ( $\left.E_{9}\right)$}

Following a failure, decisions on whether to cut back the slope, or consider the potential for supporting the failed slope, must be taken. This will largely be dictated by logistics, equipment availability, and costing. The geometry of the failure, volume of the failed mass, and in situ ground conditions would also be included in the evaluation.

\section{Technical risks (T)}

\section{Narrow ramps $\left(T_{1}\right)$}

By steepening the OSA, the horizontal projection of the pit decreases, resulting in a reduction of berm and ramp widths, steeper BSAs, or a combination thereof, each having its own consequences. The reduction in berm widths intensifies rockfall problems, and will also increase instability problems on a bench and inter-ramp scale. Decrease in the ramp widths will cause safety problems for trucks on the ramps, which can lead to a requirement for smaller units (Bozorgebrahimi, Hall, and Morin, 2005). Finally, an increase in the BSA could increase safety concerns for the operation.

The relationship between overall slope elements, as shown in Figure 6, is given in Equations [4] and [5] (Bozorgebrahimi, Hall, and Morin, 2005).

$$
\begin{aligned}
& \operatorname{Tan} \alpha=\frac{H}{X} \\
& X=\sum_{1}^{n_{1}} W_{b}+\sum_{1}^{n_{2}} W_{R}+\sum_{1}^{\left(n_{1}+n_{2}\right)} \frac{h_{b}}{\operatorname{Tan} \beta}
\end{aligned}
$$

where $\alpha$ is the overall slope angle, $H$ is slope height, $X$ the slope horizontal projection, $W_{b}$ the berm width, $W_{R}$ the ramp width, $h_{b}$ the bench height, $\beta$ the bench slope angle, and $n_{1}$ and $n_{2}$ the number of berms and ramps, respectively. With an increase in any one of the elements, problems in the others develop accumulatively.

In the Sungun case it is assumed that slope variation occurs in all three elements, with the portion of their projection. By increasing the overall slope angle, the width of the ramps is limited and smaller trucks should be used. This negative effect is a function of the maximum width of the trucks. A $30 \mathrm{~m}$ ramp width is suggested for the design sector at Sungun, assuming a $29^{\circ}$ overall slope (recommended slope in design) and $25 \mathrm{~m}$ bench heights on the pit limit (double benching). Based on the evaluation, the sum of the ramp widths is $16 \%$ of the horizontal projection of the overall slope angle and accommodates the inclusion of six ramps in the profile with inter-ramp heights of $100 \mathrm{~m}$. Thus, for decreasing and/or increasing the slope angle and its horizontal projection, the width of new ramps can be calculated. The allowable width for the largest trucks has been considered as being one quarter of the ramp width (Bozorgebrahimi, Hall, and Morin, 2005). The capacities and models of the haul trucks, mostly Komatsu, are shown in Figure 7, from which it can be seen that the steeper the overall slope angle, the narrower the ramp width in the design, and hence the requirement for smaller capacity trucks. However, with the requirement for increased production, this presents a conflict in terms of required production rate and economic slope angle.

\section{Unsuitability of mine fleet for cleanup $\left(T_{2}\right)$}

The projected failed mass will have different characteristics in comparison with initial in situ conditions, and may therefore require a different type of operation and equipment from the conventional, depending on the muckpile geometry, characteristics of the failed mass, and tonnage to be moved.

\section{Problems due to mining below the water table $\left(T_{3}\right)$}

Steeper overall slope angles can result in an increase in pit depth and the area of the lower levels, with the possible requirement for operating below the water table. The ensuing problems can include loss of access to the mining area due to flooding, increased use of explosives, increased explosive failures due to wet blast-holes, requirement for the use of special explosives, increased wear to equipment and tyres, inefficient loading and hauling, and unsafe working conditions (Morton and van Niekerk, 1993).

In order to evaluate the effect of 'wet' ground to be mined, cumulative tonnage variations below the water table have been considered in the study. With the average water level in the pit at the $1850 \mathrm{~m}$ level, the cumulative tonnage to be mined below this level for various slope angles is shown in Figure 8.

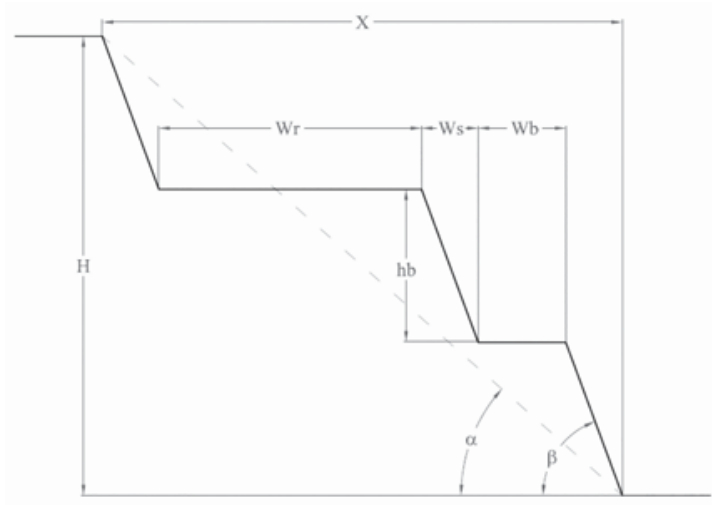

Figure 6-Components of the overall slope

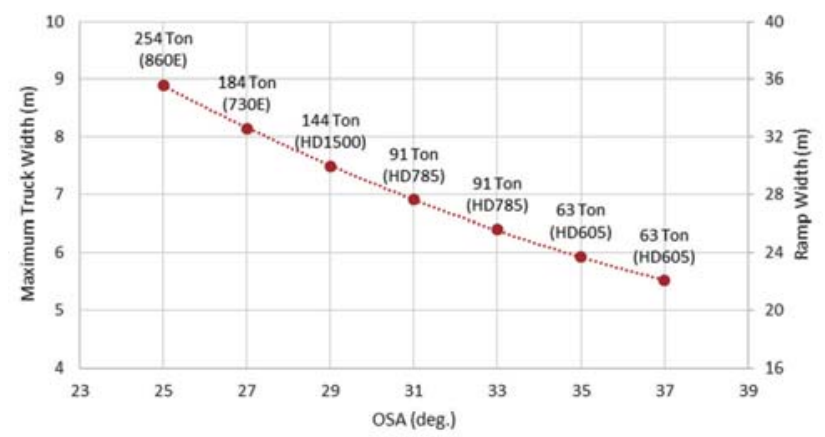

Figure 7-OSA of RS02, ramp width, truck capacity, and recommended model in Sungun 


\section{Governing risk elements through open pit slope optimization}

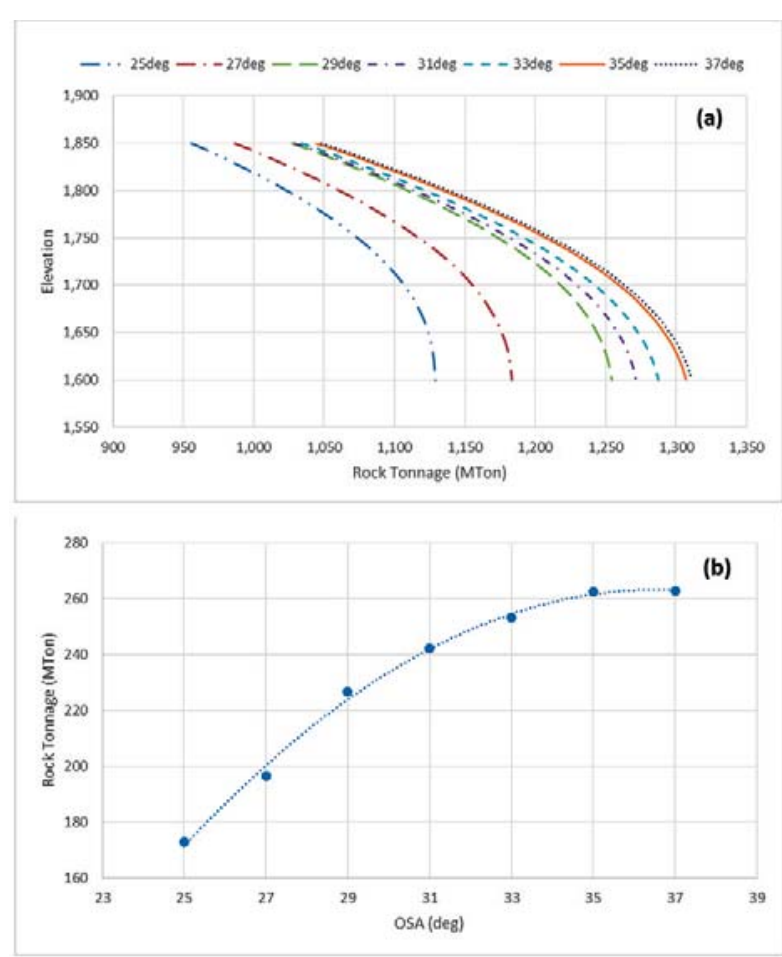

Figure 8-Wet tonnages for various slope alternatives in RS02 mining sector. (a) Cumulative rock tonnage per level, (b) total wet tonnage for varying slope angle

\section{Effect of ramp loss (T4)}

Different situations will occur in comparison with routine pit operations when the wall fails, for example the loss of a ramp. This can result in restricted access to the failed mass, as well as to operations not impacted by the wall failure, with the magnitude of the problem depending on the volume of the failure.

In the case study, with a failure in the RSO2 domain, material handling will be possible from the northern and northwestern sectors of the pit (Figure 3), with the consequence of failure being relatively insignificant in this regard.

\section{Strategic risks (S)}

\section{Loss of market share $\left(S_{1}\right)$}

In the event of a failure resulting in an ore gap developing, the mine may be unable to fulfil contractual obligations. This can result in the cancellation of such contracts, with serious implications for the operation. Depending on the size of the failure and cleanup rate, the amount of production downtime can vary significantly.

The production rate at Sungun is $40 \mathrm{Mt} / \mathrm{a}$, one-fifth of which is expected to be from RSO2 according to the mineable ore resource in the section. Assuming that resumption of the operation interrupted by a failure in the section requires cleanup of at least half of the failure volume, the downtime is calculated for each case of the OSA provided that all of the dedicated workforce and equipment in $\mathrm{RSO} 2$, i.e. one-fifth of the entire mine, were implemented. The effect of the OSA on downtime for cleanup is represented in Figure 9.

Alternatively, when the cleanup operation is accelerated by implementing half of the available operational capacity in the pit, which might also be supplied by appointing an additional contractor, the downtime on production can be more than halved, as illustrated in Figure 9.

\section{Contractual penalties $\left(S_{2}\right)$}

Once the failure occurs, the inability to fulfil corporate obligations constitutes an essential risk. If re-establishment of normal operations is time-consuming, or deferred due to unexpected problems, then depending on the contract, the mine will be subject to various consequences, depending on the failure volume, including lost or damaged equipment, and the requirement for replacing sources such as stockpiles and reserves.

\section{Stakeholder confidence $\left(S_{3}\right)$}

Although slope failure is common in open pit mines, such events decrease the company's credibility both internally and among decision-makers, as well as external stakeholders. The magnitude of the consequences would be defined by not fulfilling contracts, implications of fatalities and the effect on the workforce, as well as the implications of lost equipment that would need to be replaced.

\section{Political response $\left(\mathrm{S}_{4}\right)$}

The political response to large failures is a significant factor, and therefore consideration must be given to this factor in the long-term programme. Some of the factors that affect the political consequences are damage to other industrial sectors due to lost production, market disturbance, as well as domestic and international pressures in the event of fatalities.

\section{Regulatory risks (R)}

Injuries and fatalities among the workforce $\left(R_{1}\right.$ and $\left.R_{2}\right)$ According to Sullivan (2006), if pit slopes are covered by a reliable monitoring system and the slopes are managed by a competent geotechnical team, pit slope failure should not result in injuries or fatalities. Therefore, this issue is not normally considered in the final design, although the consequences of injuries and fatalities should be considered if the risk model is being used to justify monitoring systems.

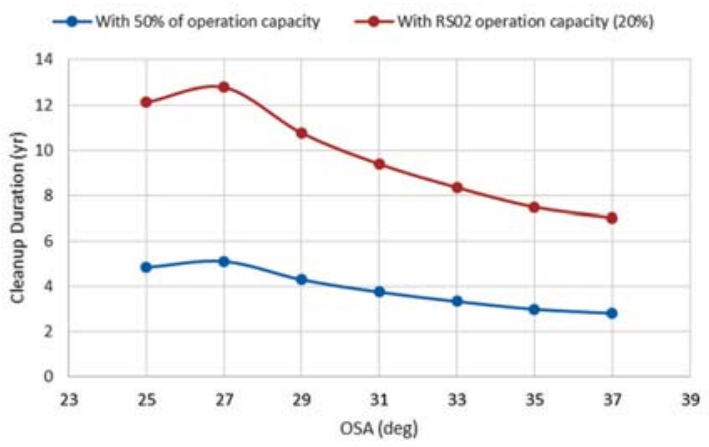

Figure 9-Downtime on production due to failure for different OSA in the RS02 domain in Sungun copper mine 


\section{Governing risk elements through open pit slope optimization}

\section{Workforce confidence $\left(R_{3}\right)$}

Unlike the economic benefits of well-managed steeper slopes, which only some of the project experts are aware of, the news of failures is widely broadcast,. In order to increase workforce confidence, it is important that the workforce is made aware of stability issues and convinced by management that monitoring and management of the slope is being carried out, and that sufficient warning will be available in the event of a failure developing.

\section{Increased legislation $\left(R_{4}\right)$}

A review of the history of legislation for open pit design shows that large-scale failures have resulted in more stingent legislation, and will in all likelihood continue to do so. Integrating this element in the analysis could benefit sustainable development in the optimization of pit slope design.

\section{Employment opportunities $\left(R_{5}\right)$}

When a mine is developed in an area, employment opportunities are created and workforce migration will occur. If the mine is closed and workers lose their jobs, adverse consequences such as social and even political disturbances can take place. It should be noted that private companies usually have less ability than governmental organizations to guarantee workforce income, and this should be considered in the risk analysis.

Environmental impact (mine waste and failed material) $\left(R_{6}\right)$ By steepening the pit slope, the volume of mineable rock (waste and ore) may be increased due to the economic viability of deeper ore, and this can lead to problems related to waste management of both dumps and tailings dams.

\section{Impact matrix}

Guidelines were provided in the previous section for making the 23 risk elements measurable. Since some of the elements are qualitative in nature, a qualitative assessment must be made in these cases. Finally all of the quantitative and qualitative performances should be assembled into an impact matrix, which would be processed by risk analysis techniques. Table II depicts the impact matrix containing the performance of the overall slope of section RSO2 in the Sungun case study. In order to study the OSA, evaluations have been made on alternatives in the range of $31 \pm 6^{\circ}$.

Golestanifar (2011) developed a soft-computing method that processes both quantitative and qualitative measures to find an optimum OSA solution. This model has been successfully implemented in the Sungun case study. The formulation of the model, as well as the details of the Sungun case study, will be covered in future publications.

\section{Table II}

Impact matrix of RS02 section in Sungun case study (Golestanifar, 2011)

\begin{tabular}{|c|c|c|c|c|c|c|c|c|c|}
\hline \multirow[t]{2}{*}{ Category } & \multirow[t]{2}{*}{ Element } & \multirow[t]{2}{*}{ Unit } & \multicolumn{7}{|c|}{ OSA alternatives (deg.) } \\
\hline & & & 25 & 27 & 29 & 31 & 33 & 35 & 37 \\
\hline \multirow[t]{9}{*}{ Economic $(E)$} & $E_{1}$ & W/O & 0.41 & 0.386 & 0.347 & 0.33 & 0.317 & 0.306 & 0.301 \\
\hline & $E_{2}$ & million\$ & 12.904 & 12.904 & 12.904 & 12.904 & 12.904 & 12.904 & 12.904 \\
\hline & $E_{3}$ & $\mathrm{kt}$ & 76.72 & 78.75 & 63.77 & 53.87 & 46.23 & 39.07 & 35.48 \\
\hline & $E_{4}$ & - & VL & VL & VL & VL & VL & VL & VL \\
\hline & $E_{5}$ & - & $\mathrm{H}$ & $\mathrm{H}$ & $\mathrm{H}-\mathrm{M}$ & $\mathrm{M}$ & $\mathrm{M}$ & M-L & $\mathrm{L}$ \\
\hline & $E_{6}$ & Mt & 197 & 207 & 175 & 152 & 136 & 122 & 114 \\
\hline & $E_{7}^{*}$ & W/O & 1.603 & 1.54 & 1.519 & 1.476 & 1.455 & 1.444 & 1.436 \\
\hline & $E_{8}$ & see Eq. [3] & 0.37 & 0.39 & 0.34 & 0.3 & 0.27 & 0.25 & 0.24 \\
\hline & $E_{9}$ & - & $\mathrm{VL}$ & $\mathrm{VL}$ & $\mathrm{L}$ & M-L & $\mathrm{H}$ & $\mathrm{VH}-\mathrm{H}$ & $\mathrm{VH}$ \\
\hline \multirow[t]{4}{*}{ Technical $(T)$} & $T_{1}$ & $\mathrm{~m}$ & 8.9 & 8.15 & 7.49 & 6.91 & 6.39 & 5.93 & 5.51 \\
\hline & $T_{2}$ & - & $\mathrm{H}$ & $\mathrm{H}$ & $\mathrm{M}$ & M-L & M-L & $\mathrm{L}$ & $\mathrm{L}$ \\
\hline & $T_{3}$ & Mt & 172.85 & 196.46 & 226.84 & 242.32 & 253.17 & 262.45 & 262.91 \\
\hline & $T_{4}$ & - & $\mathrm{M}$ & $\mathrm{M}$ & M-L & M-L & M-L & $\mathrm{L}$ & $\mathrm{L}$ \\
\hline \multirow[t]{4}{*}{ Strategic (S) } & $S_{1}$ & year & 4.8 & 5.1 & 4.3 & 3.8 & 3.3 & 3.0 & 2.8 \\
\hline & $S_{2}$ & - & $\mathrm{M}$ & $\mathrm{M}$ & $\mathrm{L}$ & $\mathrm{L}$ & L-VL & $\mathrm{L}-\mathrm{VL}$ & $\mathrm{VL}$ \\
\hline & $S_{3}$ & - & $\mathrm{H}$ & $\mathrm{H}$ & $M$ & $M$ & $M-L$ & $\mathrm{~L}$ & $\mathrm{~L}$ \\
\hline & $S_{4}$ & - & $\mathrm{H}-\mathrm{M}$ & $M$ & $M$ & $\mathrm{~L}$ & $\mathrm{~L}$ & $\mathrm{~L}$ & $\mathrm{VL}$ \\
\hline \multirow[t]{7}{*}{ Regulatory (security - social - environmental) $(R)$} & $R_{1}$ & Person & 42 & 42 & 42 & 42 & 42 & 42 & 42 \\
\hline & $R_{2}$ & Person & 42 & 42 & 42 & 42 & 42 & 42 & 42 \\
\hline & $R_{3}$ & - & $\mathrm{L}$ & $\mathrm{L}$ & $\mathrm{M}$ & $\mathrm{H}-\mathrm{M}$ & $\mathrm{VH}$ & $\mathrm{VH}$ & $\mathrm{VH}$ \\
\hline & $R_{4}$ & - & $\mathrm{L}$ & $\mathrm{L}$ & $\mathrm{M}$ & $\mathrm{H}-\mathrm{M}$ & $\mathrm{VH}$ & $\mathrm{VH}$ & $\mathrm{VH}$ \\
\hline & $R_{5}$ & - & $\mathrm{M}-\mathrm{L}$ & $M-L$ & $\mathrm{~L}$ & $\mathrm{~L}$ & $\mathrm{~L}$ & L-VL & L-VL \\
\hline & $R_{6}^{\dagger}$ & Mt & 197 & 207 & 175 & 152 & 136 & 122 & 114 \\
\hline & $R_{6}^{\ddagger}$ & Mt & 733 & 745 & 796 & 800 & 806 & 815 & 816 \\
\hline
\end{tabular}

VL: very low; L: low; M: medium; H: high; VH: very high

${ }^{*}$ Excluding pre-stripping waste, i.e. $E_{1}$.

† Cleanup residuals.

$\ddagger$ Mining waste. 


\section{Governing risk elements through open pit slope optimization}

\section{Conclusions}

Currently, open pit slopes are designed based on geotechnical programmes that include extensive drilling and laboratory testing campaigns, but also calling on the designers' experience. With the competition in global ore markets, designers are attempting to drive down the overall mining costs in all sectors. It appears, however, that advances in pit slope design are largely confined to a conventional analysis approach, with interpretation of the slope designs resulting in conservative results guided by factor of safety or probability of failure results. The latest developments using risk models are, however, faced with practical limitations that make it difficult to define a robust system with clear and valid numerical results. One of the major difficulties in developing risk models for optimum pit slope design is a lack of definition of the risk elements to the required levels for input to an analysis. When risk elements are well defined, accurate analysis can be carried out with reliable input, with logical results representing optimum pit slope angles. The result will also identify critical elements which are required as further input to the study or treated by risk management efforts.

This study is concerned with investigating developed models and classification of risk elements, and detecting their ambiguities, deficiencies, and shortcomings in order to introduce a comprehensive classification of risk elements for pit slope optimization.

A wide range of slope parameters and circumferential conditions are to be considered in the multidimensional concept of risk optimization. The 23 elements included here have been classed into four groups - economic $(E)$, technical $(T)$, strategic $(S)$, and regulatory $(R)$. The economic group consists of elements that have direct effect on pit economics, while the elements in the other groups can have indirect economic outcomes. Although certain elements have a threshold and are controlled by local regulations, others can be traded off against each other.

Depending on the governing strategy in the mine, the elements can have a variable weighting. In developing countries, various objectives such as enhancing infrastructure, updating technology, welfare of local inhabitants, or increasing skills levels can be included in the motivations for opening a mine. In this case, the range of the elements could be wide, with different validities. The elements introduced in this study are appropriate for general conditions, with specific elements considered in certain circumstances.

\section{References}

Abbaszadeh, M., Shahriar, K., SharifzAdeh, M., and Heydari, M. 2011. Uncertainty and reliability analysis applied to slope stability - a case study from Sungun copper mine. Geotechnical and Geological Engineering, vol. 29 , no. 4. pp. 581-596.

AKBari, A. and Osanloo, M. 2005. An updated and modified O'Hara cost estimating model based on world and Iran economic conditions. APCOM 2005. Proceedings of the 32nd International Symposium on Computer Applications in the Minerals Industry Conference, Tucson, Arizona, 30 March - 1 April 2005. CRC Press, Boca Raton, Florida. pp. 3-18.

Bozorgebrahimi, A., Hall, R.A., and Morin, M.A. 2005. Equipment size effects on open pit mining performance. International Journal of Surface Mining, Reclamation and Environment, vol. 19, no. 1. pp. 41-56.

CALL. R.D. and KIM. Y.C. 1978. Composite probability of instability for optimizing pit slope design. Proceedings of 19th US Symposium on Rock Mechanics, Reno, Nevada, 1-3 May 1978. Kim, Y.S. (ed.). American Rock Mechanics Association, Alexandria, Virginia.

Contreras, L.F., Le Sueur, R., and Maran, J. 2006. A case study of risk evaluation at Cerrejon mine. Proceedings of the International Symposium of Rock Slope Stability in Open Pit Mining and Civil Engineering, Cape Town, South Africa, 3-6 April 2006. Symposium Series S44. Southern African Institute of Mining and Metallurgy, Johannesburg. pp. 181-210.

DiNIS DA GAMA, C.D. 1994. Variability and uncertainty evaluations for rock slope design. Proceedings of the 1st North American Rock Mechanics Symposium, Austin, Texas. American Rock Mechanics Association, Alexandria, Virginia. pp. 547-555.

GolestANIFAR, M. 2011. Introducing a new model to pit slope optimization based on multiple risk attributes approach. MSc thesis, Tehran Science and Research Branch, Islamic Azad University, Tehran (in Persian).

Hustrulid, W. and KuchtA, M. 1995. Open Pit Mine Planning and Design, vol. I - Fundamentals. AA Balkema, Rotterdam.

MORTON, K.L. and VAN NIEKERK, F.A. 1993. A phased approach to mine dewatering. Mine Water and the Environment, vol. 12. pp. 27-33.

O'HARA, T.A. 1980. Quick guides to the evaluation of orebodies, CIM Bulletin, vol. 73. pp. 87-99.

Priest, S.D. and Brown, E.T. 1983. Probabilistic stability analysis of variable rock slopes. Transactions of the Institution of Mining and Metallurgy Section A - Mining Technology, vol. 92. pp. A1-12.

RYAn, T.M. and PrYoR, P.R. 2000. Designing catch benches and inter ramp slopes. Slope Stability in Surface Mining. Hustrulid, W., McCarter, M.K., and van Zyl, D.J.A. (eds.). SME, Littleton, Colorado. pp. 27-38.

SRK Consulting. 2006. The stability of rock slopes in large open pit mines design manual. Project no. 2004-ha62. CSIRO, Melbourne.

SRK Consulting. 2008. Mining geotechnics and slope design studies for Sungun copper mine project. NICICO, Tehran.

Stacey, P.F. 2009. Fundamentals of slope design. Guidelines for Open Pit Slope Design. Read. J.R.L. and Stacey. P.F. (eds.). CSIRO Publishing, Melbourne. pp. 1-14.

SulLivan, T.D. 2006. Pit slope design and risk - a view of the current state of the art. Proceedings of the International Symposium of Rock Slope Stability in Open Pit Mining and Civil Engineering, Cape Town, South Africa, 3-6 April 2006. Symposium Series S44. Southern African Institute of Mining and Metallurgy, Johannesburg. pp. 51-80.

TAPiA, A., Contreras, L.F., JefFeries, M.G., and StefFen, O.K.H. 2007. Risk evaluation of slope failure at Chuquicamata mine. Proceedings of the International Symposium of Rock Slope Stability in Open Pit Mining and Civil Engineering. Potvin, Y. (ed.). Australian Centre for Geomechanics, Perth. pp. 477-485.

Terbrugge, P.J., Wesseloo, J., Venter, J., and Steffen, O.K.H. 2006. A risk consequence approach to open pit slope design. Journal of the South African Institute of Mining and Metallurgy, vol. 106. pp. 503-511.

Wesseloo, J. and ReAd, J. 2009. Acceptance criteria. Guidelines for Open Pit Slope Design. Read, J.R.L., and Stacey, P.F. (eds.). CSIRO Publishing, Melbourne. pp. 221-235. 